\title{
The influence of hydrostatic pressure on DADP-type antiferroelectrics
}

\author{
R.R.Levitskii, A.P.Moina \\ Institute for Condensed Matter Physics of the National Academy of \\ Sciences of Ukraine, 1 Svientitskii St., UA-290011 Lviv, Ukraine
}

Received June 23, 1998

\begin{abstract}
We study the effects of hydrostatic pressures on deuterated $\mathrm{ND}_{4} \mathrm{D}_{2} \mathrm{PO}_{4}$ type antiferroelectric crystals. Within the four-particle cluster approximation the free energy of the crystals is calculated, and an equation for the transition temperature and explicit expressions for static dielectric permittivities of the crystals are derived. Model pressure dependences of the effective dipole moments of unit cells are proposed. Some peculiarities of the dipole moment formation in these hydrogen bonded crystals are elucidated. In particular, we show the importance of mutual polarization of the dipole moments. The theory parameters providing a satisfactory description of the experimental data for pressure dependences of transition temperature and dielectric characteristics of the considered crystals are found.
\end{abstract}

Key words: DADP, antiferroelectrics, pressure, dielectric permittivity, phase transition

PACS: $77.84 . F$

\section{Introduction}

Ammonium dihydrogen phosphate $\mathrm{NH}_{4} \mathrm{H}_{2} \mathrm{PO}_{4}$ (ADP) and ammonium dihydrogen arsenate $\mathrm{NH}_{4} \mathrm{H}_{2} \mathrm{AsO}_{4}(\mathrm{ADA})$ are those members of the $\mathrm{KH}_{2} \mathrm{PO}_{4}$ family of hydrogen bonded crystals which undergo antiferroelectric phase transitions, and it is still not clear what is the origin of this phase transition: Is it triggered by the ordering of protons on hydrogen bonds [1-5], or are the whole $\mathrm{H}_{2} \mathrm{PO}_{4}$ groups ordering units $[6,7]$ ?

High pressure studies are a tool which can shed some light on this problem, in particular, give some information about the role of hydrogen bonds and especially of their geometric parameters in the phase transition and a polarization mechanism in crystals.

Experimentally, the influence of external pressure on these crystals is studied much less than on ferroelectric representatives of the family. However, it is known that transition temperature $T_{\mathrm{N}}$ in $\mathrm{NH}_{4} \mathrm{H}_{2} \mathrm{PO}_{4}, \mathrm{ND}_{4} \mathrm{D}_{2} \mathrm{PO}_{4}, \mathrm{NH}_{4} \mathrm{H}_{2} \mathrm{AsO}_{4}$ 
and $\mathrm{ND}_{4} \mathrm{D}_{2} \mathrm{AsO}_{4}$ decreases with hydrostatic pressure linearly at low pressures $[8,9]$ (see table 1). The transition temperatures in arsenates are higher than in phosphates, but the coefficients $\left(\partial T_{\mathrm{N}} / \partial p\right)_{0}$ in $\mathrm{ND}_{4} \mathrm{D}_{2} \mathrm{PO}_{4}(\mathrm{DADP})$ and $\mathrm{ND}_{4} \mathrm{D}_{2} \mathrm{AsO}_{4}$ (DADS) are nearly equal. At higher pressures in $\mathrm{NH}_{4} \mathrm{H}_{2} \mathrm{PO}_{4}$ the dependence of $T_{\mathrm{N}}(p)$ becomes nonlinear, and at $p=33$ kbar the transition temperature in this crystal turns to zero (the ordered phase disappears) [10].

Under the uniaxial pressure $p=-\sigma_{3}$ the transition temperature in undeuterated $\mathrm{NH}_{4} \mathrm{H}_{2} \mathrm{PO}_{4}$ decreases, too, and this decrease is faster than under hydrostatic pressure [11].

Table 1. Transition temperature at ambient pressure and the initial slope $\left(\partial T_{\mathrm{N}} / \partial p\right)_{0}$ of some antiferroelectrics. The data are taken from [9].

\begin{tabular}{|c|c|c|}
\hline crystal & $T_{\mathrm{N} 0}$ & $\left(\partial T_{\mathrm{N}} / \partial p\right)_{0}$ \\
\hline $\mathrm{NH}_{4} \mathrm{H}_{2} \mathrm{PO}_{4}$ & 151.2 & -3.4 \\
$\mathrm{ND}_{4} \mathrm{D}_{2} \mathrm{PO}_{4}$ & 235.1 & -1.4 \\
$\mathrm{NH}_{4} \mathrm{H}_{2} \mathrm{AsO}_{4}$ & 216 & -1.97 \\
$\mathrm{ND}_{4} \mathrm{D}_{2} \mathrm{AsO}_{4}$ & 304 & -1.45 \\
\hline
\end{tabular}

In antiferroelectrics of the $\mathrm{NH}_{4} \mathrm{H}_{2} \mathrm{PO}_{4}$ type, a pronounced first order phase transition takes place, accompanied by a significant temperature hysteresis and jumps of both the transverse and longitudinal static dielectric permittivities. The transverse permittivity in $\mathrm{NH}_{4} \mathrm{H}_{2} \mathrm{AsO}_{4}$ and $\mathrm{ND}_{4} \mathrm{D}_{2} \mathrm{AsO}_{4}$ is much higher than in $\mathrm{NH}_{4} \mathrm{H}_{2} \mathrm{PO}_{4}$ and $\mathrm{ND}_{4} \mathrm{D}_{2} \mathrm{PO}_{4}$, respectively.

Transverse permittivity of $\mathrm{NH}_{4} \mathrm{H}_{2} \mathrm{PO}_{4}, \mathrm{NH}_{4} \mathrm{H}_{2} \mathrm{AsO}_{4}$ and $\mathrm{ND}_{4} \mathrm{D}_{2} \mathrm{AsO}_{4}$ decreases with pressure in the paraelectric phase and slightly increases in the antiferroelectric phase $[9,10]$. It should be noted that in arsenates this decrease in $\varepsilon_{1}$ at $T>T_{\mathrm{N}}$ is fairly fast (in the deuterated form faster than in the undeuterated one).

The influence of pressure on the crystal structure of the $\mathrm{KH}_{2} \mathrm{PO}_{4}$ family of antiferroelectrics has almost not been studied. However, it is known that the transition temperature in $\mathrm{NH}_{4} \mathrm{H}_{2} \mathrm{PO}_{4}$ and $\mathrm{ND}_{4} \mathrm{D}_{2} \mathrm{PO}_{4}$, as well as in $\mathrm{KH}_{2} \mathrm{PO}_{4}$ and $\mathrm{KD}_{2} \mathrm{PO}_{4}$, is a linear function of the $\mathrm{H}$-site distance $\delta$ - a separation between two possible positions of a hydrogen on the bond $\mathrm{O}-\mathrm{H} . . \mathrm{O}$ - and turns to zero in $\mathrm{NH}_{4} \mathrm{H}_{2} \mathrm{PO}_{4}$ at $\delta_{c}=0.2 \AA[12-14]$. Furthermore, at equal $\delta$ with an accuracy of $0.01 \AA$ the transition temperatures in $\mathrm{KH}_{2} \mathrm{PO}_{4}, \mathrm{~K}\left(\mathrm{H}_{1-x} \mathrm{D}_{x}\right)_{2} \mathrm{PO}_{4}, \mathrm{NH}_{4} \mathrm{H}_{2} \mathrm{PO}_{4}$, and $\mathrm{ND}_{4} \mathrm{D}_{2} \mathrm{PO}_{4}$ coincide.

In the paraelectric phase, an $\mathrm{NH}_{4} \mathrm{H}_{2} \mathrm{PO}_{4}$ crystal is isomorphic to $\mathrm{KH}_{2} \mathrm{PO}_{4}$ [1517]. This fact, along with the similarity of temperature and pressure dependences of several physical characteristics of the two crystals, implies the necessity to look for a unified description of high pressure effects in them.

In our recent papers [18-20] we developed an approach which allows us to describe consistently the influence of hydrostatic and uniaxial $p=-\sigma_{3}$ pressures (pressures which do not lower the crystals symmetry) on deuterated ferroelectric crystals of the $\mathrm{KH}_{2} \mathrm{PO}_{4}$ family. This approach is based on the model of strained 
$\mathrm{KH}_{2} \mathrm{PO}_{4}$ type crystals proposed earlier by Stasyuk et al. $[23,24]$. In $[21,22]$ we also studied the influence of external pressures on the $\mathrm{ND}_{4} \mathrm{D}_{2} \mathrm{PO}_{4}$ type antiferroelectrics.

In the present paper we slightly change the model (namely, in the way we model the pressure dependence of the Slater energies) and propose a new simple way to describe the polarization processes in antiferroelectric crystals. These changes allow us to describe the experiment for the pressure dependences of dielectric characteristics of a $\mathrm{ND}_{4} \mathrm{D}_{2} \mathrm{AsO}_{4}$ crystal ${ }^{1}$ [9], reduce the number of free parameters and to reproduce within the proton ordering model the universality of the transition temperature vs $\mathrm{H}$-site distance dependence in several crystals of this family $[12-14]$.

\section{The model of strained DADP type antiferroelectrics}

We consider a system of deuterons moving on hydrogen O-D... O bonds in the $\mathrm{ND}_{4} \mathrm{D}_{2} \mathrm{PO}_{4}$ type crystals to which an external hydrostatic pressure and electric field $E_{i}(i=1,2,3)$ along one of the crystallographic axis $a, b, c$ are applied.

The calculations are performed within the four-particle cluster approximation which allows one to take into account the strong short-range correlations between deuterons adequately. The four-particle cluster Hamiltonian of such a system, with the effective long-range interactions (dipole-dipole as well as indirect deuterondeuteron interactions via lattice vibrations) taken into account in the mean field approximation, reads $[21,22]$ :

$$
\begin{aligned}
& \hat{H}_{q 4}^{i}=V\left[\frac{\sigma_{q 1}}{2} \frac{\sigma_{q 2}}{2}+\frac{\sigma_{q 2}}{2} \frac{\sigma_{q 3}}{2}+\frac{\sigma_{q 3}}{2} \frac{\sigma_{q 4}}{2}+\frac{\sigma_{q 4}}{2} \frac{\sigma_{q 1}}{2}\right]+ \\
& \quad+U\left[\frac{\sigma_{q 1}}{2} \frac{\sigma_{q 3}}{2}+\frac{\sigma_{q 2}}{2} \frac{\sigma_{q 4}}{2}\right]+\Phi \frac{\sigma_{q 1}}{2} \frac{\sigma_{q 2}}{2} \frac{\sigma_{q 3}}{2} \frac{\sigma_{q 4}}{2}-\sum_{f} \frac{z_{q f}^{i}}{\beta} \frac{\sigma_{q f}}{2} .
\end{aligned}
$$

Two eigenvalues of Ising spin $\sigma_{q f}= \pm 1$ are assigned to two equilibrium positions of a deuteron on the $f$-th bond in the $q$-th cell.

The parameters of short-range configurational interactions $V=\left(\varepsilon-w_{1}\right) / 2, U=$ $\left(\varepsilon+w_{1}\right) / 2, \Phi=2 \varepsilon-8 w+2 w_{1}$ are the functions of the Slater energies $\varepsilon=\varepsilon_{s}-\varepsilon_{a}$, $w=\varepsilon_{1}-\varepsilon_{a}, w_{1}=\varepsilon_{0}-\varepsilon_{a}$, where $\varepsilon_{a}, \varepsilon_{s}, \varepsilon_{1}$, and $\varepsilon_{0}$ are the energies of the lateral, up-down, single-ionized and double-ionized deuteron configurations, respectively. Let us mention that the energy of lateral configurations in these antiferroelectric crystals is the lowest.

The fields $z_{q f}^{i}$ include the effective cluster fields $\Delta_{q f}^{i}$ created by the sites neighbouring to the $q f$-th site, external electric field $E_{i}$, and the long-range deuterondeuteron interactions taken into account in the mean field approximation

$$
z_{q f}^{i}=\beta\left[-\Delta_{q f}^{i}+\sum_{q^{\prime} f^{\prime}} J_{f f^{\prime}}\left(q q^{\prime}\right) \frac{\left\langle\sigma_{q^{\prime} f^{\prime}}\right\rangle}{2}+\mu_{q f}^{i} E_{i}\right],
$$

\footnotetext{
${ }^{1}$ In our earlier paper $[21,22]$ we did not perform calculations for $\mathrm{ND}_{4} \mathrm{D}_{2} \mathrm{AsO}_{4}$, but only for $\mathrm{ND}_{4} \mathrm{D}_{2} \mathrm{PO}_{4}$.
} 
The influence of external pressure on the considered system is modelled on the basis of the ideas of $[23,24]$ and $[25]$ in the following way.

It is known that the Slater energies $\varepsilon, w, w_{1}$ and the components of the longrange interaction matrix $J_{f f^{\prime}}\left(q q^{\prime}\right)$ are proportional to the square of the separation between two possible positions of a deuteron on a bond - D-site distance $\delta$. Assuming the linear

$$
\delta=\delta_{0}+\delta_{1} p
$$

dependence of the D-site distance $\delta$ of $\mathrm{ND}_{4} \mathrm{D}_{2} \mathrm{PO}_{4}$ and $\mathrm{ND}_{4} \mathrm{D}_{2} \mathrm{AsO}_{4}$ crystals on hydrostatic pressure (according to $[26,27]$ the variation of $\delta$ with pressure in $\mathrm{KH}_{2} \mathrm{PO}_{4}$ and $\mathrm{KD}_{2} \mathrm{PO}_{4}$ is linear, indeed, only that $\delta_{0}$ and $\delta_{1}$ are temperature dependent), we expand $\varepsilon, w, w_{1}$, and $J_{f f^{\prime}}\left(q q^{\prime}\right)$ in powers of pressure up to the linear terms. However, there can be other mechanisms of the pressure influence on the energy parameters of the model. Those mechanisms we take into account by expanding $\varepsilon, w, w_{1}$, and $J_{f f^{\prime}}\left(q q^{\prime}\right)$ in powers of components of lattice strain tensor up to the linear terms. We obtain

$$
\begin{gathered}
\varepsilon=\varepsilon^{0}\left[1-\frac{2}{S} \frac{\delta_{1}}{\delta_{0}} \sum_{j=1}^{3} \varepsilon_{j}\right]+\sum_{i=1}^{3} \delta_{1 i} \varepsilon_{i}, \quad w=w^{0}\left[1-\frac{2}{S} \frac{\delta_{1}}{\delta_{0}} \sum_{j=1}^{3} \varepsilon_{j}\right]+\sum_{i=1}^{3} \delta_{2 i} \varepsilon_{i}, \\
w_{1}=w_{1}^{0}\left[1-\frac{2}{S} \frac{\delta_{1}}{\delta_{0}} \sum_{j=1}^{3} \varepsilon_{j}\right]+\sum_{i=1}^{3} \delta_{3 i} \varepsilon_{i} .
\end{gathered}
$$

(in our earlier works we did not take into account the influence of the pressure changes in the D-site distance on the Slater energies), and

$$
J_{f f^{\prime}}\left(q q^{\prime}\right)=J_{f f^{\prime}}^{(0)}\left(q q^{\prime}\right)\left[1-\frac{2}{S} \frac{\delta_{1}}{\delta_{0}} \sum_{j=1}^{3} \varepsilon_{j}\right]+\sum_{j=1}^{3} \psi_{f f^{\prime}}^{j}\left(q q^{\prime}\right) \varepsilon_{j} .
$$

Here $S=S_{11}+2 S_{12}+2 S_{13}+S_{22}+2 S_{23}+S_{33} ; S_{i j}$ are the elastic compliances of the crystals. To avoid an explicit dependence of the Hamiltonian on pressure $p$, we express the latter in terms of the resulting strain $\sum_{j} \varepsilon_{j}$.

It is understood that above the transition point $\delta_{k 1}=\delta_{k 2}$, and $\psi_{f f^{\prime}}^{1}\left(q q^{\prime}\right)=$ $\psi_{f f^{\prime}}^{2}\left(q q^{\prime}\right)$. In the above expansions we take into account only the diagonal components of strain tensor $\varepsilon_{1}, \varepsilon_{2}, \varepsilon_{3}$ and neglect piezoelectric strains $\varepsilon_{4}, \varepsilon_{5}, \varepsilon_{6}$ which must arise if an electric field is applied (piezomodules $d_{14}, d_{25}, d_{36}$ are different from zero).

In $[23,24]$ Stasyuk et al. showed that if one takes into account the lattice strains and neglects the changes with pressure in the dipole moment of hydrogen bond $\mu=e \delta$, then application of external pressure to ferroelectric crystals of the DKDP type leads to renormalization of the created by long range interactions mean fields by terms proportional to the mean values of quasispins $\eta_{q f}=\left\langle\sigma_{q f}\right\rangle$ and strains $\varepsilon_{i}$. The same follows from (4) in the mean field approximation if $\delta_{1} / \delta_{0}=0$.

Taking into account the symmetry of the mean values of quasispins $\left\langle\sigma_{q f}\right\rangle=$ $\eta_{q f}^{i}=\operatorname{Sp}\left\{\sigma_{q f} \exp \left(-\beta \hat{H}_{q 4}^{i}\right)\right\} / \operatorname{Sp} \exp \left(-\beta \hat{H}_{q 4}^{i}\right)$ :

$$
\eta_{q 13}^{x, y}=-\eta_{q 1}^{x, y}=\eta_{q 3}^{x, y}, \quad \eta_{q 24}^{x, y}=\eta_{q 2}^{x, y}=-\eta_{q 4}^{x, y}, \quad \eta_{q 14}^{z}=\eta_{q 1}^{z}=\eta_{q 4}^{z}, \quad \eta_{q 23}^{z}=\eta_{q 2}^{z}=\eta_{q 3}^{z},
$$


and effective dipole moments

$\mu_{1}=\mu_{3}^{1}=-\mu_{1}^{1}, \mu_{2}=\mu_{2}^{2}=-\mu_{4}^{2}, \mu_{2}^{1}=\mu_{4}^{1}=\mu_{1}^{2}=\mu_{3}^{2}=0, \mu_{3}=\mu_{1}^{3}=\mu_{2}^{3}=\mu_{3}^{3}=\mu_{4}^{3}$,

presenting $\eta_{q f}^{i}$ as a sum of two terms: a modulated spontaneous part and a uniaxial one induced by the external electric field

$$
\begin{aligned}
& \eta_{q f}^{i}=\eta_{f} \mathrm{e}^{i \boldsymbol{k}_{Z} \boldsymbol{R}_{q}}+\eta_{f E_{i}}, \\
& \eta=-\eta_{1}=\eta_{2}=\eta_{3}=-\eta_{4} ; \\
& \eta_{3 E_{1}}=-\eta_{1 E_{1}}, \quad \eta_{2 E_{1}}=-\eta_{4 E_{1}} ; \quad \eta_{3 E_{2}}=-\eta_{1 E_{2}}, \quad \eta_{2 E_{2}}=-\eta_{4 E_{2}} ; \\
& \eta_{1 E_{3}}=\eta_{2 E_{3}}=\eta_{3 E_{3}}=\eta_{4 E_{3}}
\end{aligned}
$$

$\left(\boldsymbol{k}_{Z}=\frac{1}{2}\left(\boldsymbol{b}_{1}+\boldsymbol{b}_{2}+\boldsymbol{b}_{3}\right), \boldsymbol{b}_{1}, \boldsymbol{b}_{2}, \boldsymbol{b}_{3}\right.$ are the basic vectors of the reciprocal lattice, $\mathrm{e}^{i \boldsymbol{k}_{Z} \boldsymbol{R}_{q}}= \pm 1$ ), we exclude the cluster fields $\Delta_{q f}^{i}$ from the expressions for $z_{q f}^{i}$, the symmetry of which is the same as of the corresponding $\eta_{q f}^{i}$. For this purpose, we use the condition that the mean values $\left\langle\sigma_{q f}\right\rangle$, calculated within the four-particle and single-particle cluster approximation, that is, with Hamiltonian (1) and with

$$
\hat{H}_{q f}^{i}=-\frac{z_{q f}^{i}-\Delta_{q f}^{i}}{\beta} \frac{\sigma_{q f}}{2},
$$

must coincide. We obtain

$$
\begin{aligned}
& z_{q 13}^{x}=\frac{1}{2} \ln \frac{1+\eta_{q 13}^{x}}{1-\eta_{q 13}^{x}}+\beta\left[\nu_{a}\left(\boldsymbol{k}_{Z}\right) \eta \mathrm{e}^{i \boldsymbol{k}_{Z} \boldsymbol{R}_{q}}+\nu_{a}(0) \eta_{13 E_{1}}+\frac{\mu_{1} E_{1}}{2}\right], \\
& z_{q 24}^{x}=\frac{1}{2} \ln \frac{1+\eta_{q 24}^{x}}{1-\eta_{q 24}^{x}}+\beta\left[\nu_{a}\left(\boldsymbol{k}_{Z}\right) \eta \mathrm{e}^{i \boldsymbol{k}_{Z} \boldsymbol{R}_{q}}+\nu_{a}(0) \eta_{24 E_{1}}\right], \\
& z_{q 13}^{y}=\frac{1}{2} \ln \frac{1+\eta_{q 13}^{y}}{1-\eta_{q 13}^{y}}+\beta\left[\nu_{a}\left(\boldsymbol{k}_{Z}\right) \eta \mathrm{e}^{i \boldsymbol{k}_{Z} \boldsymbol{R}_{q}}+\nu_{a}(0) \eta_{13 E_{2}}\right], \\
& z_{q 24}^{y}=\frac{1}{2} \ln \frac{1+\eta_{q 24}^{y}}{1-\eta_{q 24}^{y}}+\beta\left[\nu_{a}\left(\boldsymbol{k}_{Z}\right) \eta \mathrm{e}^{i \boldsymbol{k}_{Z} \boldsymbol{R}_{q}}+\nu_{a}(0) \eta_{24 E_{2}}+\frac{\mu_{2} E_{2}}{2}\right], \\
& z_{q 14}^{z}=\frac{1}{2} \ln \frac{1+\eta_{q 14}^{z}}{1-\eta_{q 14}^{z}}+\beta\left[-\nu_{a}\left(\boldsymbol{k}_{Z}\right) \eta \mathrm{e}^{i \boldsymbol{k}_{Z} \boldsymbol{R}_{q}}+\nu_{a}(0) \eta_{E_{3}}+\frac{\mu_{3} E_{3}}{2}\right], \\
& z_{q 23}^{z}=\frac{1}{2} \ln \frac{1+\eta_{q 23}^{z}}{1-\eta_{q 23}^{z}}+\beta\left[\nu_{a}\left(\boldsymbol{k}_{Z}\right) \eta \mathrm{e}^{i \boldsymbol{k}_{Z} \boldsymbol{R}_{q}}+\nu_{a}(0) \eta_{E_{3}}+\frac{\mu_{3} E_{3}}{2}\right],
\end{aligned}
$$

where the averages $\eta_{q f}^{i}$ are

$$
\begin{aligned}
\eta_{q 13}^{x, y} & =\frac{2 \sinh z_{q 13}^{x, y} \cosh z_{q 24}^{x, y}+2 b \sinh z_{q 13}^{x, y}}{D^{x, y}}, \quad \eta_{q 24}^{x, y}=\frac{2 \sinh z_{q 24}^{x, y} \cosh z_{q 13}^{x, y}+2 b \sinh z_{q 24}^{x, y}}{D^{x, y}}, \\
\eta_{q 14}^{z} & =\frac{a \sinh \left(z_{q 14}^{z}+z_{q 23}^{z}\right)+\sinh \left(z_{q 14}^{z}-z_{q 23}^{z}\right)+2 b \sinh z_{q 14}^{z}}{D^{z}}, \\
\eta_{q 23}^{z} & =\frac{a \sinh \left(z_{q 14}^{z}+z_{q 23}^{z}\right)-\sinh \left(z_{q 14}^{z}-z_{q 23}^{z}\right)+2 b \sinh z_{q 23}^{z}}{D^{z}},
\end{aligned}
$$


and

$$
\begin{aligned}
& D^{x, y}=2 \cosh z_{q 13}^{x, y} \cosh z_{q 24}^{x, y}+2 b\left(\cosh z_{q 13}^{x, y}+\cosh z_{q 24}^{x, y}\right)+a+d, \\
& D^{z}=a \cosh \left(z_{q 14}^{z}+z_{q 23}^{z}\right)+\cosh \left(z_{q 14}^{z}-z_{q 23}^{z}\right)+2 b\left(\cosh z_{q 14}^{z}+\cosh z_{q 23}^{z}\right)+d+1, \\
& a=\exp (-\beta \varepsilon), \quad b=\exp (-\beta w), \quad d=\exp \left(-\beta w_{1}\right) .
\end{aligned}
$$

The quantities $\nu_{a}(\boldsymbol{k})$ where $\left.\boldsymbol{k}=\boldsymbol{k}_{Z}, 0\right)$ and $\nu_{c}(0)$ are the eigenvalues

$$
\begin{aligned}
& \nu_{a}(\boldsymbol{k})=\nu_{a}^{0}(\boldsymbol{k})\left[1-\frac{2}{S} \frac{\delta_{1}}{\delta_{0}} \sum_{i=1}^{3} \varepsilon_{i}\right]+\sum_{i} \psi_{a i}(\boldsymbol{k}) \varepsilon_{i}, \nu_{c}(0)=\nu_{c}^{0}(0)\left[1-\frac{2}{S} \frac{\delta_{1}}{\delta_{0}} \sum_{i=1}^{3} \varepsilon_{i}\right]+\sum_{i} \psi_{c i}(0) \varepsilon_{i}, \\
& \nu_{a}^{0}(\boldsymbol{k})=\frac{1}{4}\left[J_{11}^{(0)}(\boldsymbol{k})-J_{13}^{(0)}(\boldsymbol{k})\right] ; \quad \nu_{c}^{0}(0)=\frac{1}{4}\left[J_{11}^{(0)}(0)+2 J_{12}^{(0)}(0)+J_{13}^{(0)}(0)\right], \\
& \psi_{a i}(\boldsymbol{k})=\frac{1}{4}\left[\psi_{11}^{i}(\boldsymbol{k})-\psi_{13}^{i}(\boldsymbol{k})\right] ; \quad \psi_{c i}(0)=\frac{1}{4}\left[\psi_{11}^{i}(0)+2 \psi_{12}^{i}(0)+\psi_{13}^{i}(0)\right],
\end{aligned}
$$

of the long-range interaction matrix Fourier-transforms

$$
J_{f f^{\prime}}^{(0)}(\boldsymbol{k})=\sum_{\boldsymbol{R}_{q}-\boldsymbol{R}_{q^{\prime}}} J_{f f^{\prime}}^{(0)}\left(q q^{\prime}\right) \mathrm{e}^{-\boldsymbol{k}\left(\boldsymbol{R}_{q}-\boldsymbol{R}_{q^{\prime}}\right)}, \quad \psi_{f f^{\prime}}^{i}(\boldsymbol{k})=\sum_{\boldsymbol{R}_{q}-\boldsymbol{R}_{q^{\prime}}} \psi_{f f^{\prime}}^{i}\left(q q^{\prime}\right) \mathrm{e}^{-\boldsymbol{k}\left(\boldsymbol{R}_{q}-\boldsymbol{R}_{q^{\prime}}\right)} .
$$

The strains $\varepsilon_{i}$ and the order parameter $\eta=\lim _{E_{1} \rightarrow 0} \eta^{i}$ are to be determined from the thermodynamic equilibrium conditions

$$
\frac{1}{\bar{v}} \frac{\partial f}{\partial \eta}=0 ; \quad \frac{1}{\bar{v}} \frac{\partial f}{\partial \varepsilon_{i}}=-p_{i}
$$

where $f$ is the free energy of a crystal when no electric field is applied

$$
f=\frac{F}{N}=\frac{\bar{v}}{2} \sum_{i j} c_{i j}^{0} \varepsilon_{i} \varepsilon_{j}-[2 w-\varepsilon]+2 \nu_{a}\left(\boldsymbol{k}_{Z}\right) \eta^{2}+2 T \ln \frac{2}{\left(1-\eta^{2}\right) D},
$$

$c_{i j}^{(0)}$ are the so-called "seed" elastic constants of a crystal, describing the elasticity of a "host" lattice - a fictitious lattice without deuterons; $\bar{v}=v / k_{\mathrm{B}} ; v$ is the cell volume, $k_{\mathrm{B}}$ is the Boltzmann constant; $D=1+a+d+\cosh 2 z+4 b \cosh z, z=$ $\frac{1}{2} \ln \frac{1+\eta}{1-\eta}+\beta \nu_{a}\left(\boldsymbol{k}_{Z}\right) \eta$.

The system of equations for $\eta$ and $\varepsilon_{i}$ reads:

$$
\eta=\frac{1}{D}(\sinh 2 z+2 b \sinh z), \quad-p_{i}=\sum_{j} c_{i j}^{0} \varepsilon_{j}-F_{\text {deu }}
$$

where

$$
\begin{aligned}
F_{\text {deu }} & =\frac{2 \delta_{2 i}-\delta_{1 i}}{\bar{v}}+\frac{2}{\bar{v}}\left(\psi_{a i}\left(\boldsymbol{k}_{Z}\right)-\frac{2}{S} \frac{\delta_{1}}{\delta_{0}} \nu_{a}^{0}\left(\boldsymbol{k}_{Z}\right)\right) \eta^{2}- \\
& -\frac{2}{\bar{v} D}\left(4 b\left(\delta_{2 i}-\frac{2}{S} \frac{\delta_{1}}{\delta_{0}} w^{0}\right) \cosh z+a\left(\delta_{1 i}-\frac{2}{S} \frac{\delta_{1}}{\delta_{0}} \varepsilon^{0}\right)+d\left(\delta_{3 i}-\frac{2}{S} \frac{\delta_{1}}{\delta_{0}} w_{1}^{0}\right)\right) *
\end{aligned}
$$


is a contribution of the deuteron subsystem to crystal elasticity. Since determination of this contribution lies beyond the scope of the present paper, we may safely consider instead of (9) the system

$$
\eta=\frac{1}{D}(\sinh 2 z+2 b \sinh z), \quad-p_{i}=\sum_{j} c_{i j} \varepsilon_{j}
$$

where $c_{i j}$ are elastic constants of the whole crystal, being determined from an experiment.

The temperature of the first order phase transition is found from the following condition for the values of thermodynamic potential $g(\eta, T, p)=f+\bar{v} \sum_{i} \varepsilon_{i} p_{i}$

$$
g\left(\eta, T_{\mathrm{N}}, p\right)=g\left(0, T_{\mathrm{N}}, p\right)
$$

the order parameter and lattice strains obeying the system (10).

\section{Dielectric properties of strained DADP type antiferroelec- trics}

It is assumed that the polarization of a crystal is triggered by the deuteron ordering, therefore,

$$
P_{i}=\sum_{f} \frac{\mu_{q f}^{i}}{v} \frac{\left\langle\sigma_{q f}\right\rangle}{2} .
$$

Different from the zero macroscopic polarization of antiferroelectric crystals is determined by those parts of the mean values of quasispins which are induced by the external electric field

$$
P_{1}=2 \frac{\mu_{1}}{v} \eta_{13 E_{1}}, \quad P_{2}=2 \frac{\mu_{2}}{v} \eta_{24 E_{2}}, \quad P_{3}=\frac{4 \mu_{3}}{v} \eta_{E_{3}} .
$$

Differentiating (12) with respect to $E_{i}$ one can easily obtain the expressions for the corresponding static dielectric susceptibilites of a clamped $\left(\varepsilon_{i}=\right.$ const $)$ crystal of the $\mathrm{ND}_{4} \mathrm{D}_{2} \mathrm{PO}_{4}$ type

$$
\begin{aligned}
& \chi_{1,2}^{\varepsilon}(0, T, p)=\left(\frac{\partial P_{1,2}}{\partial E_{1,2}}\right)_{\varepsilon_{i}}=\frac{\beta \mu_{1,2}^{2}}{2 v}\left[\frac{2 \varkappa_{1}}{D-2 \varkappa_{1} \varphi_{1}^{\eta}}+\frac{2 \varkappa_{2}}{D-2 \varkappa_{2} \varphi_{1}^{\eta}}\right] ; \\
& \chi_{3}^{\varepsilon}(0, T, p)=\left(\frac{\partial P_{3}}{\partial E_{3}}\right)_{\varepsilon_{i}}=\frac{\beta \mu_{3}^{2}}{v} \frac{4 \varkappa_{3}}{D-2 \varkappa_{3} \varphi_{3}^{\eta}} ;
\end{aligned}
$$

where we use the notations

$$
\begin{aligned}
& \varkappa_{1}=1+b \cosh z, \varkappa_{2}=\cosh 2 z+b \cosh z-\eta^{2} D, \varkappa_{3}=a+b \cosh z ; \\
& \varphi_{1}^{\eta}=\frac{1}{1-\eta^{2}}+\beta \nu_{a}(0), \quad \varphi_{3}^{\eta}=\frac{1}{1-\eta^{2}}+\beta \nu_{c}(0),
\end{aligned}
$$


and, thereupon, the static dielectric permittivities

$$
\varepsilon_{i}^{\varepsilon}(0, T, p)=\varepsilon_{i \infty}+4 \pi \chi_{i}^{\varepsilon}(0, T, p) .
$$

Let us note that in the paraelectric phase at ambient pressure and at $w, w_{1} \rightarrow \infty$, (13) coincides with the corresponding expressions of $[2,3]$ and $[28,29]$.

The static dielectric permittivities of the mechanically free crystal ( $p=$ const) $\varepsilon_{i}^{F}(0, T, p)$ are related to $(14)$ by $[30]$

$$
\begin{aligned}
& \varepsilon_{1}^{F}(0, T, p)=\varepsilon_{1}^{\varepsilon}(0, T, p)+4 \pi d_{14}^{2} c_{44}^{E}, \\
& \varepsilon_{2}^{F}(0, T, p)=\varepsilon_{2}^{\varepsilon}(0, T, p)+4 \pi d_{25}^{2} c_{55}^{E}, \\
& \varepsilon_{3}^{F}(0, T, p)=\varepsilon_{3}^{\varepsilon}(0, T, p)+4 \pi d_{36}^{2} c_{66}^{E},
\end{aligned}
$$

where $d_{i j}$ are the piezomodules, and $c^{E}$ are the elastic constants of a short-circuited crystal [31].

Our main task is to determine the pressure dependences of the effective dipole moments $\mu_{i}$. In the case of ferroelectrics $\mathrm{KD}_{2} \mathrm{PO}_{4}$ and $\mathrm{RbD}_{2} \mathrm{PO}_{4}$, a satisfactory quantitative description of temperature curves of the spontaneous polarization and a longitudinal static dielectric permittivity at different values of hydrostatic pressure have been obtained by means of the following simple expressions [32]:

$$
\frac{1}{\mu_{1}} \frac{\partial \mu_{1}}{\partial p}=\frac{1}{\delta} \frac{\partial \delta}{\partial p}+\frac{1}{a} \frac{\partial a}{\partial p}, \quad \frac{1}{\mu_{3}} \frac{\partial \mu_{3}}{\partial p}=\frac{1}{\delta} \frac{\partial \delta}{\partial p}+\frac{1}{c} \frac{\partial c}{\partial p}
$$

found on the basis of the model assumptions about the mechanism of polarization in hydrogen-bonded crystals of this type: The effective dipole moment $\mu_{i}$, created by displacements of heavy ions and, perhaps, by redistribution of electronic density which are, in turn, triggered by the deuteron ordering, is proportional to $\delta a_{i}$, where $a_{i}$ is the corresponding lattice constant.

Using (16), for the pressure dependences of coefficients $f_{i}=\mu_{i}^{2} / v$ we obtain

$$
\begin{aligned}
& k_{f 1}=\left(\frac{\partial f_{1}}{\partial p}\right)_{p=0}=f_{1}^{(0)}\left[2 \frac{\delta_{1}}{\delta_{0}}+\frac{\varepsilon_{1}-\varepsilon_{2}-\varepsilon_{3}}{p}\right] \\
& k_{f 3}=\left(\frac{\partial f_{3}}{\partial p}\right)_{p=0}=f_{3}^{(0)}\left[2 \frac{\delta_{1}}{\delta_{0}}+\frac{\varepsilon_{3}-\varepsilon_{1}-\varepsilon_{2}}{p}\right] .
\end{aligned}
$$

In our earlier work $[21,22]$ we used (17) and (18) to predict the possible pressure dependences of dielectric permittivities of $\mathrm{ND}_{4} \mathrm{D}_{2} \mathrm{PO}_{4}$, for which no experimental results were available; at that moment we were not aware of the data for $\mathrm{ND}_{4} \mathrm{D}_{2} \mathrm{AsO}_{4}$ [9]. However, our later numerical calculations showed that for $\mathrm{ND}_{4} \mathrm{D}_{2} \mathrm{AsO}_{4}$ (to which large dipole moments and rapid changes in dielectric permittivity with external pressure are particular [9]), expressions (17) and (18) do not yield a good description of experimental data, though qualitatively the behaviour of dielectric permittivity with pressure is reproduced.

We believe that in this case in order to improve an agreement with the experimental data, as an additional mechanism of dipole moment formation, one should 
take into account mutual polarization of the dipoles created by the deuteron ordering.

We estimate the contribution of this mechanism to the pressure dependence of the dipole moment from the following speculations.

Consider a simple model of a polarized lattice, when each unit cell possesses a dipole moment, whose size is much less than the distances between the dipoles (the distances between the nearest dipoles are the lattice constants $a$ and $c$ ). Up to the terms linear in the external field, the transverse polarization of an antiferroelectric crystal (naturally, induced by this external field) reads:

$$
P_{1}=\frac{2 \mu_{1}}{v} \frac{\partial \eta_{13 E_{1}}}{\partial E_{01}} E_{01}=\frac{\mu_{1}^{2}}{v} \tilde{\chi}_{1} E_{01}=\frac{d_{1}}{v}
$$

where (see (13))

$$
\tilde{\chi}_{1}=\frac{1}{2}\left[\frac{2 \varkappa_{1}}{D-2 \varkappa_{1} \varphi_{1}^{\eta}}+\frac{2 \varkappa_{2}}{D-2 \varkappa_{2} \varphi_{1}^{\eta}}\right]
$$

$d_{1}$ is the transverse dipole moment of a unit cell, $v$ is the unit cell volume, and $\mu_{1}$ is the effective dipole moment.

To find $\mu_{1}$ we take into account the fact that the field acting on a dipole is different from the external one $E_{01}$, but also includes a field created by other dipoles of a crystal. Assuming that the dipole moment of the $i$-th unit cell $\boldsymbol{d}_{i}$ is proportional to the entire field

$$
\boldsymbol{d}_{i}=\hat{\alpha}\left(\boldsymbol{E}_{0}+\sum_{j} \frac{3\left(\boldsymbol{n}_{i j} \boldsymbol{d}_{j}\right) \boldsymbol{n}_{i j}-\boldsymbol{d}_{j}}{R_{i j}^{3}}\right),
$$

( $\hat{\alpha}$ is the polarizability tensor, $\boldsymbol{n}_{i j}$ is the unit vector directed from the dipole $\boldsymbol{d}_{j}$ to $\boldsymbol{d}_{i} ; R_{i j}$ is the distance between these dipoles). We neglect a finiteness of the crystal volume, and assume that all the dipoles, as well as the field created by them, are oriented along the external field $E_{01}$. Then the internal field is

$$
d \sum_{j} \frac{3 \cos ^{2} \beta_{i j}-1}{R_{i j}^{3}}
$$

$\beta$ is the angle between vectors $\boldsymbol{n}_{i j}$ and $\boldsymbol{d}_{j}$, determined by

$$
\cos \beta_{i j}=\frac{\left(\boldsymbol{n}_{i j} \boldsymbol{d}_{i j}\right)}{d}=\frac{x}{\sqrt{x^{2}+y^{2}+z^{2}}} ;
$$

$(x, y, z)$ are the Cartesian coordinates of the dipole $\boldsymbol{d}_{j}$ if $\boldsymbol{d}_{i}$ is placed in the origin. Substituting the latter expression into (21), we obtain

$$
d_{1}=\frac{\alpha_{1} E_{01}}{1-\alpha_{1} K_{1}} ; \quad K_{1}=\sum_{\boldsymbol{R}} \frac{2 x^{2}-y^{2}-z^{2}}{\left(x^{2}+y^{2}+z^{2}\right)^{5 / 2}}=\sum_{n_{1} n_{2} n_{3}} \frac{2 a^{2} n_{1}^{2}-b^{2} n_{2}^{2}-c^{2} n_{3}^{2}}{\left(a^{2} n_{1}^{2}+b^{2} n_{2}^{2}+c^{2} n_{3}^{2}\right)^{5 / 2}},
$$


$a, b, c$ are lattice constants; $n_{1}, n_{2}, n_{3}$ are numerals, and $n_{1}^{2}+n_{2}^{2}+n_{3}^{2} \neq 0$. Comparing (23) and (19) and differentiating the obtained expression with respect to pressure, we find that

$$
\mu_{1}^{2}=\frac{1}{\tilde{\chi}_{1}} \frac{\alpha_{1}}{1-\alpha_{1} K_{1}}, \quad \frac{1}{\mu_{1}^{2}} \frac{\partial \mu_{1}^{2}}{\partial p}=\frac{1}{\alpha_{1}} \frac{\partial \alpha_{1}}{\partial p}\left[1+\tilde{\chi}_{1} K_{1} \mu_{1}^{2}\right]+\tilde{\chi}_{1} \mu_{1}^{2} \frac{\partial K_{1}}{\partial p},
$$

where

$$
\begin{aligned}
& \frac{\partial K_{1}}{\partial p} p=\sum_{n_{1} n_{2} n_{3}} \frac{a^{2} n_{1}^{2}\left(4 R^{2}-5 r_{1}\right) \varepsilon_{1}-b^{2} n_{2}^{2}\left(2 R^{2}+5 r_{1}\right) \varepsilon_{2}-c^{2} n_{3}^{2}\left(2 R^{2}+5 r_{1}\right) \varepsilon_{3}}{R^{7 / 2}} \\
& R=\sqrt{a^{2} n_{1}^{2}+b^{2} n_{2}^{2}+c^{2} n_{3}^{2}}, \quad r_{1}=2 a^{2} n_{1}^{2}-b^{2} n_{2}^{2}-c^{2} n_{3}^{2}
\end{aligned}
$$

Here we neglect the variation of $\tilde{\chi}_{1}$ with pressure, which is very weak, indeed. It turns out that to find $K_{1}$ and $\partial K_{1} / \partial p$, we may consider only the values of $n_{i}=-2,-1 \ldots 2$ (we take into account only two surroundings of a site).

The value of $\frac{1}{\alpha_{1}} \frac{\partial \alpha_{1}}{\partial p}$ is chosen so that it corresponds to the rate of the pressure changes in the square of effective dipole moment $\mu_{1}^{2}$ in the case when the mutual polarization of dipoles is not taken into account, namely:

$$
\frac{1}{\alpha_{1}} \frac{\partial \alpha_{1}}{\partial p}=2\left(\frac{\delta_{1}}{\delta_{0}}+\frac{\varepsilon_{1}}{p}\right)
$$

Therefore, with a sufficient accuracy we can think that coefficient $k_{f 1}$ of the considered antiferroelectrics reads:

$$
k_{f 1}=\left[2\left(1+\tilde{\chi}_{1} K_{1}\left(\mu_{1}^{0}\right)^{2}\right)\left(\frac{\delta_{1}}{\delta_{0}}+\frac{\varepsilon_{1}}{p}\right)+\tilde{\chi}_{1}\left(\mu_{1}^{0}\right)^{2} \frac{\partial K_{1}}{\partial p}-\frac{\varepsilon_{1}+\varepsilon_{2}+\varepsilon_{3}}{p}\right],
$$

where $\mu_{1}^{0}$ is the effective dipole moment of a unit cell at ambient pressure.

The dielectric permittivity should be determined as a derivative of polarization with respect to the complete field $E_{1}=E_{01}+d_{1} K_{1}=E_{01} /\left(1-\alpha_{1} K_{1}\right)$. Then, instead of (13), we obtain

$$
\chi_{1}(0, T, p)=\left(1-\alpha_{1} K_{1}\right) \frac{\mu_{1}^{2}}{v} \tilde{\chi}_{1}=\frac{\mu_{1}^{2}}{v} \frac{\tilde{\chi}_{1}}{1+\mu_{1}^{2} \tilde{\chi}_{1} K_{1}} .
$$

Let us mention that the difference between (13) and (25) is larger, the stronger the crystal lattice differs from the cubic one; at $a=c, K_{1} \equiv 0$.

Similarly, for a longitudinal susceptibility we obtain

$$
\chi_{3}(0, T, p)=\left(1-\alpha_{3} K_{3}\right) \frac{\mu_{3}^{2}}{v} \tilde{\chi}_{3}=\frac{\mu_{3}^{2}}{v} \frac{\tilde{\chi}_{3}}{1+\mu_{3}^{2} \tilde{\chi}_{3} K_{3}} .
$$

where

$$
\tilde{\chi}_{3}=\frac{4 \varkappa_{3}}{D-2 \varkappa_{3} \varphi_{3}^{\eta}}
$$




$$
k_{f_{3}}=\left[2\left(1+\tilde{\chi}_{3} K_{3}\left(\mu_{3}^{0}\right)^{2}\right)\left(\frac{\delta_{1}}{\delta_{0}}+\frac{\varepsilon_{3}}{p}\right)+\tilde{\chi}_{3}\left(\mu_{3}^{0}\right)^{2} \frac{\partial K_{3}}{\partial p}-\frac{\varepsilon_{1}+\varepsilon_{2}+\varepsilon_{3}}{p}\right] \tilde{\chi}_{3}
$$

and the expressions for $K_{3}$ and $\partial K_{3} / \partial p$ read:

$$
\begin{aligned}
& K_{3}=\sum_{n_{1} n_{2} n_{3}} \frac{-a^{2} n_{1}^{2}-b^{2} n_{2}^{2}+2 c^{2} n_{3}^{2}}{\left(a^{2} n_{1}^{2}+b^{2} n_{2}^{2}+c^{2} n_{3}^{2}\right)^{5 / 2}}, \quad r_{3}=-a^{2} n_{1}^{2}-b^{2} n_{2}^{2}+2 c^{2} n_{3}^{2} ; \\
& \frac{\partial K_{3}}{\partial p} p=\sum_{n_{1} n_{2} n_{3}} \frac{-a^{2} n_{1}^{2}\left(2 R^{2}+5 r_{3}\right) \varepsilon_{1}-b^{2} n_{2}^{2}\left(2 R^{2}+5 r_{3}\right) \varepsilon_{2}+c^{2} n_{3}^{2}\left(4 R^{2}-5 r_{3}\right) \varepsilon_{3}}{R^{7 / 2}} .
\end{aligned}
$$

The differences between $k_{f_{1}}$ and $k_{f_{3}}$, calculated from (17) and (24), and from (18) and (27), respectively, are more significant, the larger effective dipole moments $\mu_{i}$ are. Since the longitudinal moments of ferroelectrics $\mathrm{KD}_{2} \mathrm{PO}_{4}$ and $\mathrm{RbD}_{2} \mathrm{PO}_{4}$ are comparatively small, their pressure dependences calculated from (18) and (27) practically coincide. The main contribution to these dependences results from the term $\frac{1}{\alpha_{3}} \frac{\partial \alpha_{3}}{\partial p}$, that is, they are determined by the pressure changes in the D-site distances, whereas the mutual polarization of dipoles is unimportant here.

\section{Numerical analysis}

With the help of the presented theory we are going to describe the effects of hydrostatic pressure in highly deuterated antiferroelectric crystals $\mathrm{ND}_{4} \mathrm{D}_{2} \mathrm{PO}_{4}$ and $\mathrm{ND}_{4} \mathrm{D}_{2} \mathrm{AsO}_{4}$.

For a numerical estimate of the temperature and pressure dependences of the calculated above physical characteristics of the crystals, we need to set the values of the following parameters:

- Slater energies $\varepsilon^{0}, w^{0}, w_{1}^{0}$, parameters of the long-range interactions $\nu_{a}\left(\boldsymbol{k}_{Z}\right)$, $\nu_{a}(0), \nu_{c}(0)$, constants $f_{3}^{(0)}=\left(\mu_{3}^{(0)}\right)^{2} / v^{0}$ and $f_{1}^{(0)+}=\left(\mu_{1}^{(0)}\right)^{2} / v^{0}$ which occur in the expressions for longitudinal and transverse permittivities, respectively. All these parameters correspond to unstrained crystals.

- deformation potentials $\delta_{i j}, \psi_{a j}\left(\boldsymbol{k}_{Z}\right), \psi_{a j}(0)$ i $\psi_{c j}(0)$, ratio $\delta_{1} / \delta_{0}$ which describes the rate of the pressure changes in the D-site distance $\delta$.

- elastic constants $c_{i j}$

As parameters describing an unstrained state of $\mathrm{ND}_{4} \mathrm{D}_{2} \mathrm{PO}_{4}$, we choose those found in $[21,28,29]$ and which provide a satisfactory agreement with the experimental data for the transition temperature, specific heat, static and dynamic dielectric permittivities of the crystal at the atmospheric pressure. The corresponding parameters for $\mathrm{ND}_{4} \mathrm{D}_{2} \mathrm{AsO}_{4}$ were found in [32]. Everywhere, $w_{1} \rightarrow \infty$. The calculations were performed for $\mathrm{N}\left(\mathrm{H}_{1-x} \mathrm{D}_{x}\right)_{4}\left(\mathrm{H}_{1-x} \mathrm{D}_{x}\right)_{2} \mathrm{PO}_{4}$ with $T_{\mathrm{N} 0}=235 \mathrm{~K}$, for which the dependence of the transition temperature $T_{\mathrm{N}}$ on hydrostatic pressure is known [8] (hereafter, it is denoted simply as $\mathrm{ND}_{4} \mathrm{D}_{2} \mathrm{PO}_{4}$.) 
The deformation potentials $\delta_{i j}, \psi_{a j}\left(\boldsymbol{k}_{Z}\right), \psi_{a j}(0)$ and $\psi_{c j}(0)$, as well as parameter $\delta_{1} / \delta_{0}$ are determined by fitting the theoretical results for the pressure dependence of the transition temperature of the crystals to the corresponding experimental data ${ }^{2}$.

As our calculations show, the deformation potentials $\delta_{i j}$ can be safely put equal to zero. This means that the contribution of the lattice strains to the pressure dependence of the Slater energies is negligibly small, and the latter results mainly from the pressure changes in the D-site distance $\delta$.

However, that is not the case for the parameters of long-range interactions. Here we have to set the values of the deformation potentials $\psi_{a j}\left(\boldsymbol{k}_{Z}\right), \psi_{a j}(0)$, and $\psi_{c j}(0)$. The $\psi_{a j}\left(\boldsymbol{k}_{Z}\right)$ enter the equation for order parameter $(9)$, whereas the $\psi_{a j}(0)$, and $\psi_{c j}(0)$ occur only in expressions for dielectric permittivities.

We tried to set the values of $\psi_{a j}\left(\boldsymbol{k}_{Z}\right)$ in a consistent way, estimating them from the relation

$$
\frac{\psi_{a i}\left(\boldsymbol{k}_{Z}\right)\left(\mathrm{ND}_{4} \mathrm{D}_{2} \mathrm{PO}_{4}\right)}{\psi_{a i}\left(\boldsymbol{k}_{Z}\right)\left(\mathrm{ND}_{4} \mathrm{D}_{2} \mathrm{AsO}_{4}\right)}=\frac{\nu_{a}^{0}\left(\boldsymbol{k}_{Z}\right)\left(\mathrm{ND}_{4} \mathrm{D}_{2} \mathrm{PO}_{4}\right)}{\nu_{a}^{0}\left(\boldsymbol{k}_{Z}\right)\left(\mathrm{ND}_{4} \mathrm{D}_{2} \mathrm{AsO}_{4}\right)} \text {. }
$$

Since the values of dielectric permittivities are not very sensitive to small changes in parameters $\nu_{a}(0)=\nu_{a}^{0}(0)\left[1-2 / S \delta_{1} / \delta_{0} \sum_{i} \varepsilon_{i}\right]+\sum_{i} \psi_{a i}(0) \varepsilon_{i}$ or $\nu_{c}(0)=\nu_{c}^{0}(0)[1-$ $\left.2 / S \delta_{1} / \delta_{0} \sum_{i} \varepsilon_{i}\right]+\sum_{i} \psi_{c i}(0) \varepsilon_{i}$, for the sake of simplicity we assume that $\psi_{a i}(0)=$ $\psi_{c i}(0)=0$.

As elastic constants of $\mathrm{ND}_{4} \mathrm{D}_{2} \mathrm{PO}_{4}$ we take the elements of a matrix inverse to the elastic compliances matrix $s_{i j}^{E}$, measured at ambient pressure [31]. As far as $\mathrm{ND}_{4} \mathrm{D}_{2} \mathrm{AsO}_{4}$ is concerned, the corresponding experimental data are available only for an undeuterated form [33]. Taking into account the fact that elastic constants of deuterated crystals are, as a rule, higher that those of their undeuterated forms, we fix the values of deformation potentials $\psi_{a i}\left(\boldsymbol{k}_{Z}\right)$ calculated with $(28)$, and obtain an agreement with the experimental dependence $T_{\mathrm{N}}(p)$ by changing $c_{i j}$ from $c_{i j}^{+}$ of the undeuterated crystal up to $\sim 1.5 c_{i j}^{+}$. Since no experimental data for the elastic constants of the crystals in the ordered phase are available, we calculated the transition temperature of these crystals at different pressures and different but close to $c_{i j}^{+}$trial values of $c_{i j}^{-}$, choosing those which provide the best fit to the experimental data.

The values of the theory parameters which yield the best agreement of the theoretical results with the available experimental data for the temperature and pressure dependences of thermodynamic and dielectric characteristics of the considered crystals are given in tables 2 and 3. Further experimental pressure studies of these crystals will help us to find more precise values of the theory parameters.

In numerical calculations we minimize the thermodynamic potential with respect to the order parameter $\eta$ and find the strains $\varepsilon_{i}$ from the three latter equa-

\footnotetext{
${ }^{2}$ Actually, the ratio $\delta_{1} / \delta_{0}$ is not supposed to be a fitting parameter, for it can be measured experimentally, as it was for ferroelectric KDP and DKDP crystals. However, since no $\delta(p)$ dependence for DADP or DADA has been reported yet, we treat $\delta_{1} / \delta_{0}$ as a free parameter of the theory.
} 
Table 2. The theory parameters for two crystals, $\psi_{a i}=\psi_{a i}\left(\boldsymbol{k}_{Z}\right)$.

\begin{tabular}{|c|c|ccccc|cc|}
\hline \multirow{2}{*}{ crystal } & $T_{\mathrm{N} 0}$ & $\varepsilon^{0}$ & $w^{0}$ & $\nu_{a}^{0}\left(\boldsymbol{k}_{Z}\right) \nu_{a}^{0}(0)$ & $\nu_{c}^{0}(0)$ & $f_{1}^{(0)}$ & $f_{3}^{(0)}$ \\
\cline { 2 - 7 } & \multicolumn{7}{|c|}{$(\mathrm{K})$} \\
\hline $\mathrm{ND}_{4} \mathrm{D}_{2} \mathrm{PO}_{4}$ & 235 & 77 & 709 & 85.75 & -54 & -17 & 837 & 245 \\
$\mathrm{ND}_{4} \mathrm{D}_{2} \mathrm{AsO}_{4}$ & 286.3 & 105 & 810 & 103.65 & -38.5 & & 1720 \\
\hline
\end{tabular}

\begin{tabular}{|c|c|c|ccccc|}
\hline crystal & $\partial T_{\mathrm{N}} / \partial p$ & $\delta_{1} / \delta_{0}$ & $\psi_{a 1}^{-}$ & $\psi_{a 2}^{-}$ & $\psi_{a 3}^{-}$ & $\psi_{a 1}^{+}$ & $\psi_{a 3}^{+}$ \\
\cline { 2 - 7 } & $(\mathrm{K} / \mathrm{kbar})$ & $\left(10^{-3} \mathrm{kbar}^{-1}\right)$ & \multicolumn{4}{|c}{$(\mathrm{K})$} \\
\hline $\mathrm{ND}_{4} \mathrm{D}_{2} \mathrm{PO}_{4}$ & -1.4 & -3.65 & -165 & -175 & 80 & -170 & 80 \\
$\mathrm{ND}_{4} \mathrm{D}_{2} \mathrm{AsO}_{4}$ & -1.35 & -3.0 & -160 & -180 & 90 & -170 & 90 \\
\hline
\end{tabular}

Table 3. Elastic constants $c_{i j}$ (units of $10^{5}$ bar) for the two crystals.

\begin{tabular}{|c|cccccccccc|}
\hline crystal & $c_{11}^{0+}$ & $c_{12}^{0+}$ & $c_{13}^{0+}$ & $c_{33}^{0+}$ & $c_{11}^{0-}$ & $c_{12}^{0-}$ & $c_{13}^{0-}$ & $c_{22}^{0-}$ & $c_{23}^{0-}$ & $c_{23}^{0-}$ \\
\hline $\mathrm{ND}_{4} \mathrm{D}_{2} \mathrm{PO}_{4}$ & 6.59 & 0.53 & 1.92 & 3.28 & 6.24 & 0.4 & 1.66 & 6.4 & 1.5 & 3.48 \\
$\mathrm{ND}_{4} \mathrm{D}_{2} \mathrm{AsO}_{4}$ & 6.4 & 0.9 & 2.4 & 3.85 & 6.4 & 0.9 & 2.4 & 6.3 & 2.2 & 3.85 \\
\hline
\end{tabular}

tions (10); the transition temperature is determined from condition (11). Results of the numerical calculations are given in the figures below.

In figure 1 we plot the dependence of the phase transition temperature of $\mathrm{ND}_{4} \mathrm{D}_{2} \mathrm{PO}_{4}$ and $\mathrm{ND}_{4} \mathrm{D}_{2} \mathrm{AsO}_{4}$ on hydrostatic pressure along with experimental points of $[8,9]$. Naturally, a perfect fit of theoretical results to the experimen-

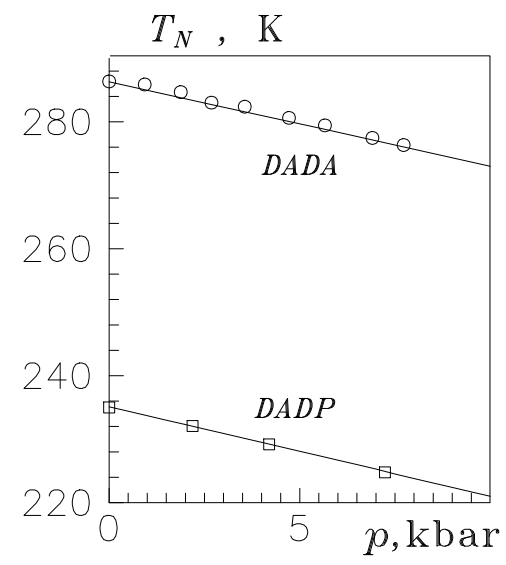

Figure 1. The transition temperature of $\mathrm{ND}_{4} \mathrm{D}_{2} \mathrm{PO}_{4}$ and $\mathrm{ND}_{4} \mathrm{D}_{2} \mathrm{AsO}_{4}$ as a function of hydrostatic pressure. Experimental points are taken from [8] $-\square$ and [9] -0 .

tal data is obtained. At pressures below $10 \mathrm{kbar}$, the dependences $T_{\mathrm{N}}(p)$ are linear with nearly equal coefficients $k_{T}=\partial T_{\mathrm{N}} / \partial p=-1.4 \mathrm{~K} / \mathrm{kbar}$.

It should be noted that the points of $T_{\mathrm{N}}$ vs $\delta$ at different values of hydrostatic 
pressure (the pressure dependence of $\delta$ is calculated with the help of $\delta_{1} / \delta_{0}$ from table 2) of the two antiferroelectrics considered here, as well as the corresponding points of the ferroelectrics $\mathrm{KD}_{2} \mathrm{PO}_{4}, \mathrm{RbD}_{2} \mathrm{PO}_{4}, \mathrm{KD}_{2} \mathrm{AsO}_{4}$, and $\mathrm{RbD}_{2} \mathrm{AsO}_{4}$ under hydrostatic pressure and of $\mathrm{K}\left(\mathrm{H}_{0.13} \mathrm{D}_{0.87}\right){ }_{2} \mathrm{PO}_{4}$ under uniaxial pressure $p=-\sigma_{3}$ lie on a single line [34]. It means that the universality of the transition temperature vs H-site distance dependence observed experimentally in [12-14] is reproduced in this theory, and even expanded to other crystals of this family and to uniaxial pressure $p=-\sigma_{3}$.

In figure 2 we present temperature curves of the transverse static dielectric permittivity $\varepsilon_{1}(0, T, p)$ of $\mathrm{ND}_{4} \mathrm{D}_{2} \mathrm{AsO}_{4}$ at different values of hydrostatic pressure along with the experimental points of [9]. The experimental data correspond to a clamped crystal [9], therefore, the theoretical values of $\varepsilon_{1}(0, T, p)$ were calculated with (14).

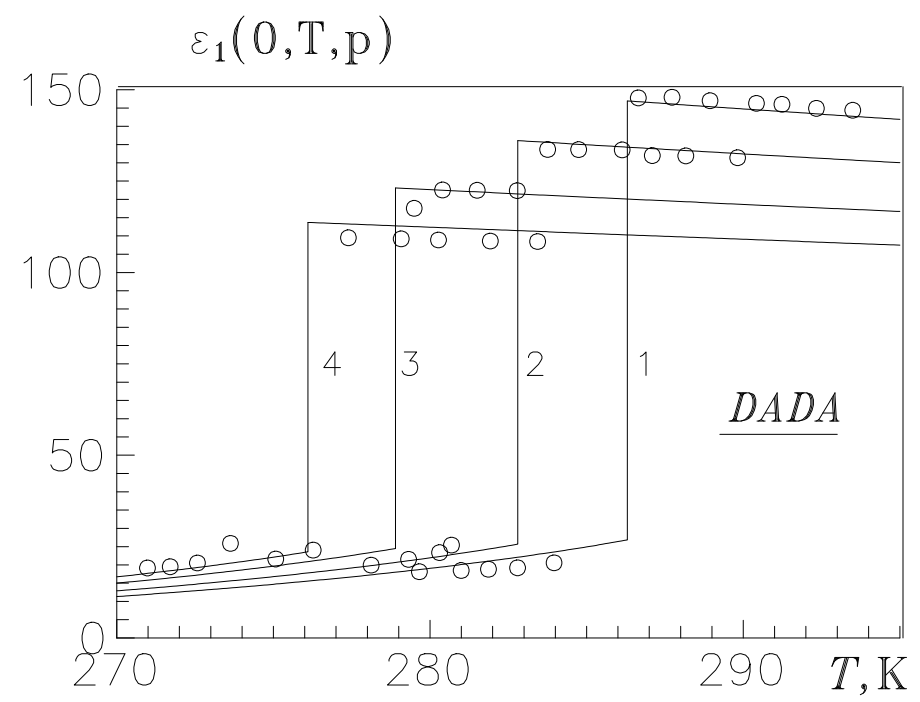

Figure 2. The temperature dependence of the transverse static dielectric permittivity of $\mathrm{ND}_{4} \mathrm{D}_{2} \mathrm{AsO}_{4}$ at different values of external hydrostatic pressure $p(\mathrm{kbar})$ : a) $1-0.001 ; 2-2.62 ; 3-5.6 ; 4-7.68$. Experimental points are taken from [9].

For $\mathrm{ND}_{4} \mathrm{D}_{2} \mathrm{AsO}_{4}$, as well as for other arsenates $\left(\mathrm{KH}_{2} \mathrm{AsO}_{4}[35]\right.$ and $\mathrm{NH}_{4} \mathrm{H}_{2} \mathrm{AsO}_{4}$ $[9])$, the high values of the transverse dielectric permittivity in the paraelectric phase, as compared with those in the corresponding phosphates, are peculiar. The transverse permittivity in $\mathrm{ND}_{4} \mathrm{D}_{2} \mathrm{AsO}_{4}$ decreases with pressure fairly fast, whereas a decrease of the transition temperature is comparatively slow. The coefficient $k_{f 1}$ was calculated from (24), which provides a satisfactory agreement with the experimental data at temperatures far from critical. In the antiferroelectric phase $\varepsilon_{1}(0, T, p)$ slightly increases with pressure.

In figure 3 we give the temperature curves of the transverse $\varepsilon_{1}(0, T, p)$ and longitudinal $\varepsilon_{3}(0, T, p)$ static dielectric permittivities of $\mathrm{ND}_{4} \mathrm{D}_{2} \mathrm{PO}_{4}$ at different values of hydrostatic pressure along with the experimental points [31] for ambient pressure. Unfortunately, we are not aware of any experimental work, where the 
pressure influence of dielecrtic characteristics of deuterated DADP was studied; therefore, the presented graphs only illustrate the plausible pressure dependences of $\varepsilon_{1}(0, T, p)$ and $\varepsilon_{3}(0, T, p)$. Theoretical values of the permittivities of a free crystal were calculated from (15), using the experimental data for elastic compliances $c_{44}^{E}$ and $c_{66}^{E}$ and for piezomodules $d_{14}$ and $d_{36}$ of [31]. Since in $\mathrm{ND}_{4} \mathrm{D}_{2} \mathrm{PO}_{4} d_{14} \ll d_{36}$, the difference between the values of longitudinal permittivity of free and clamped crystals is several times larger than that between the values of the transverse one. The quantities $k_{f 1}$ and $k_{f 3}$ were calculated from (24) and (27). For $\varepsilon_{1}(0, T, p)$ a fair description of experimental data is obtained, whereas for $\varepsilon_{3}(0, T, p)$ an agreement with the experiment is somewhat worse. Perhaps, this agreement can be improved if one explicitly takes into account the influence of piezoelectric strain $\varepsilon_{6}$.
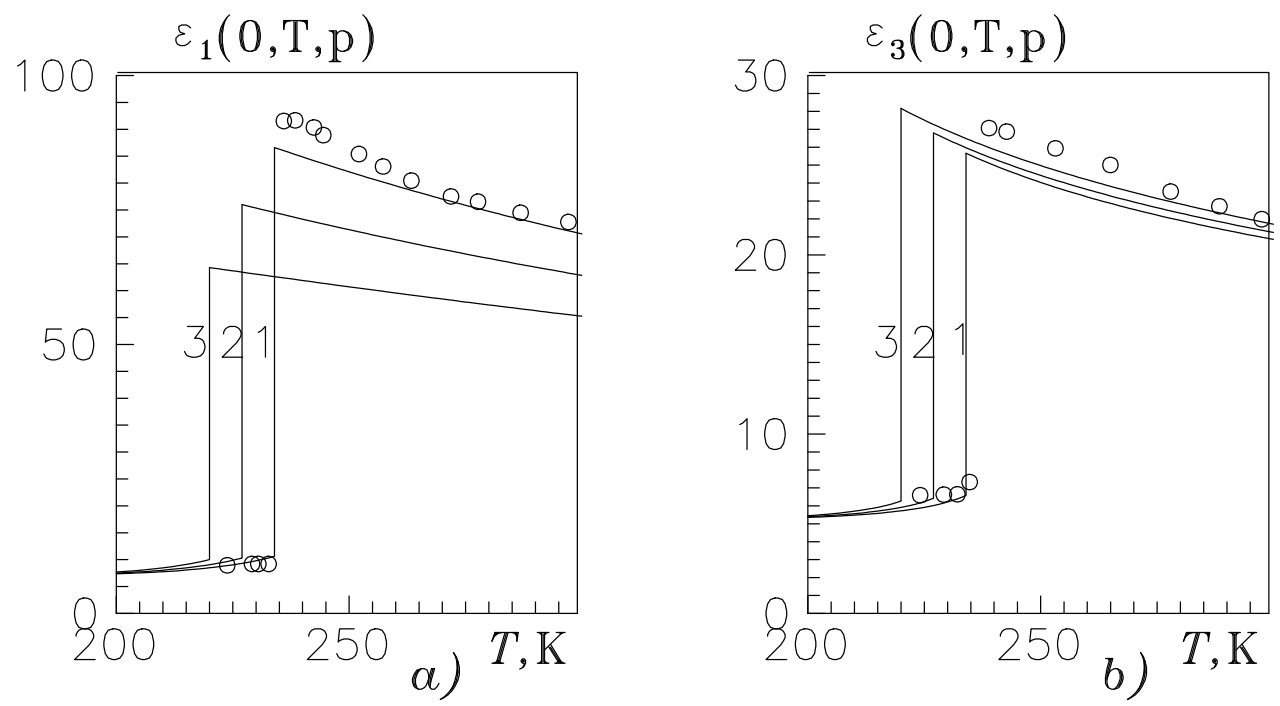

Figure 3. The transverse (a) and longitudinal (b) static dielectric permittivities of $\mathrm{ND}_{4} \mathrm{D}_{2} \mathrm{PO}_{4}$ as functions of temperature at different values of hydrostatic pressure $p$ (kbar): $1, \bigcirc[31]-0.001 ; 2-5 ; 3-10$.

As one can see, the dependences of transverse static dielectric permittivities of $\mathrm{ND}_{4} \mathrm{D}_{2} \mathrm{PO}_{4}$ and $\mathrm{ND}_{4} \mathrm{D}_{2} \mathrm{AsO}_{4}$ on hydrostatic pressure are similar - a strong decrease in $\varepsilon_{1}(0, T, p)$ in the paraelectric phase and a weak increase in the antiferroelectric phase. The pressure changes in the longitudinal permittivity are mainly the shifts to lower temperatures due to the lowering of the transition temperature. Besides, $\varepsilon_{3}(0, T, p)$ slightly decreases with pressure in the both phases.

\section{Concluding remarks}

In this paper we propose a theory of strained by hydrostatic pressure antiferroelectric deuterated crystals of the $\mathrm{ND}_{4} \mathrm{D}_{2} \mathrm{PO}_{4}$ type. It should be noted that the theory can be easily generalized to the case of uniaxial pressure $p=-\sigma_{3}$ and other pressures which do not lower the system symmetry. In fact, for this purpose one should only change the system of equations for the lattice strains (10). 
Within the four-particle cluster approximation in the short-range interactions and the mean field approximation in the long-range interactions we derived an equation for the transition temperature and explicit expressions for dielectric characteristics of the crystals. A set of free parameters was found, providing a good agreement between the presented theory and the available experimental data. An importance of the D-site distance in the phase transition and a dielectric response of the crystals is shown. We have also shown that as an essential mechanism of the dipole moment formation in these crystals, one should take into account the processes of mutual polarization of dipole moments of unit cells.

\section{Acknowledgements}

We would like to thank Prof. I. Stasyuk for useful discussions, valuable remarks, and his continuous interest in our work.

This work was supported by the Foundation for Fundamental Investigations of the Ukrainian Ministry of Science and Technology, project No.04/171.

\section{References}

1. Nagamiya T. On the theory of dielectric, piezoelectric and elastic properties of $\mathrm{NH}_{4} \mathrm{H}_{2} \mathrm{PO}_{4}$. // Progr. Theor. Phys., 1952, vol. 7, No 3, p. 275-284.

2. Havlin S., Litov E., Sompolinsky H. Unified model for the transverse electric susceptibility in $\mathrm{KH}_{2} \mathrm{PO}_{4}$ and $\mathrm{NH}_{4} \mathrm{H}_{2} \mathrm{PO}_{4}$-type crystals. // Phys. Rev. B, 1976, vol. 14, No 3, p. $1297-1302$.

3. Havlin S. Longitudinal and transverse dielectric constants of KDP-type ferro- and antiferroelectrics. // Ferroelectrics, 1987, vol. 71, p. 183-223.

4. Levitskii R.R., Korinevskii N.A., Stasyuk I.V. Distribution functions and thermodynamical properties of $\mathrm{KD}_{2} \mathrm{PO}_{4}$ and $\mathrm{ND}_{4} \mathrm{D}_{2} \mathrm{PO}_{4}$ type crystals. // Phys.Stat.Sol.(b), 1978, vol. 88, No 1, p. 51-63.

5. Stasyuk I.V., Levitskii R.R. Dynamic theory of antiferroelectrics with hydrogen bonds of $\mathrm{NH}_{4} \mathrm{H}_{2} \mathrm{PO}_{4}$ type. // Bull. Ac. Sci. USSR, Ser, Fiz., 1971, vol.35, No 9, p. 1775-1778.

6. Kasahara M., Tatsuzaki I. Raman scattering in $\mathrm{NH}_{4} \mathrm{H}_{2} \mathrm{PO}_{4}$ and $\mathrm{ND}_{4} \mathrm{D}_{2} \mathrm{PO}_{4}$. // Jap. Journ. Appl. Phys., 1985, vol. 24, Suppl. 24-2, p. 920-922.

7. Kasahara M., Tokunaga M., Tatsuzaki I. Raman scattering study on the phase transition of $\mathrm{NH}_{4} \mathrm{H}_{2} \mathrm{PO}_{4}$ and $\mathrm{ND}_{4} \mathrm{D}_{2} \mathrm{PO}_{4}$. // J. Phys. Soc. Jpn., 1986, vol. 55, No 1, p. 367-376.

8. Skalyo J., Jr., Frazer B.C., Shirane G., Daniels W.B. The pressure dependence of the transition temperature in KDP and ADP. // J. Phys. Chem. Solids, 1969, vol. 30, p. 2045-2051.

9. Gesi K., Ozawa K. Effect of hydrostatic pressure on the antiferroelectric phase transitions in ammonium arsenate $\mathrm{NH}_{4} \mathrm{H}_{2} \mathrm{AsO}_{4}$ and deuterated analogue. // J. Phys. Soc. Jap., 1984, vol. 53, No 12, p. 4405-4412.

10. Samara G.A. Vanishing of the ferroelectric and antiferroelectric states in $\mathrm{KH}_{2} \mathrm{PO}_{4}$ type crystals at high pressure. // Phys. Rev. Lett., 1971, vol. 27, No 2, p. 103-106.

11. Romanyuk M.O., Stadnyk V.J., Chervonii R.G. To be published. 
12. Piltz R.O., McMahon M.I., Nelmes R.J. Neutron-diffraction studies of the geometric isotope effect in H-ordering transitions. // Ferroelectrics, 1990, vol.108, p. 271-276.

13. McMahon M.I., Piltz R.O., Nelmes R.J. Neutron-diffraction studies of the relationship between $T_{c}$ and H-bond dimensions in H-ordering transitions. // Ferroelectrics, 1990, vol. 108, p. 277-282.

14. Nelmes R.J., McMahon M.I., Piltz R.O., Wright N.G. High pressure neutrondiffraction studies of $\mathrm{KH}_{2} \mathrm{PO}_{4}$-type phase transitions as $T_{c}$ tends to $0 \mathrm{~K}$. // Ferroelectrics, 1991, vol. 124, p. 355-360.

15. Landolt-Börnstein. Numerical Data and Functional Relationships in Science and Technology. New Series. Group III: Crystal and Solid State Physics, vol. 16. Ferroelectrics and Related Substances, subvolume b: Non-oxides. Springer-Verlag Berlin-Heidelberg - New York, 1982.

16. Ueda R. Crystal structure of ammonium dihydrogen phosphate $\mathrm{NH}_{4} \mathrm{H}_{2} \mathrm{PO}_{4}$. // J. Phys. Soc. Jpn., 1948, vol. 3, No 4, p. 328-333.

17. Keeling R.O. Jr., Pepinsky R. An X-ray diffraction study on the transition in $\mathrm{NH}_{4} \mathrm{H}_{2} \mathrm{PO}_{4}$ at $148^{\circ}$ K. // Z. Kristallogr., 1955, vol. 106, No 3, p. 236-285.

18. I.V. Stasyuk, R.R. Levitskii, I.R. Zachek, A.P. Moina, A.S. Duda. Hydrostatic pressure influence on phase transition and physical properties of $\mathrm{KD}_{2} \mathrm{PO}_{4}$-type ferroelectrics. // Cond. Matt. Phys., 1996, No 8, p. 129-156.

19. Stasyuk I.V., Levitskii R.R., Zachek I.R , Moina A.P., Duda A.S. Hydrostatic pressure influence on phase transition and physical properties of $\mathrm{KD}_{2} \mathrm{PO}_{4}$-type ferroelectrics. Preprint ICMP-96-12E, Lviv, 1996, 42 p.

20. Stasyuk I.V., Levitskii R.R., Zachek I.R., Duda A.S., Moina A.P., Romanyuk N.O., Stadnyk V.J., Chervony R.G., Shcherbina Ye.V. Uniaxial pressure influence on phase transition and physical properties of highly deuterated $\mathrm{KH}_{1-x} \mathrm{D}_{x} \mathrm{PO}_{4}$-type ferroelectrics. Preprint ICMP-96-18E, Lviv, 1996, 36 p.

21. Levitskii R.R., Moina A.P., Zachek I.R. External pressure influence on phase transition and physical properties of $\mathrm{ND}_{4} \mathrm{D}_{2} \mathrm{PO}_{4}$-type antiferroelectrics. / Preprint ICMP-97-3E, Lviv, 1997, 36 p.

22. Levitskii R.R., Zachek I.V., Moina A.P. Influence of external pressure on phase transitions and physical properties of DADP type antiferroelectrics. // Journ. Phys. Studies, 1997, vol.1, No 4, p. 576-587 (in Ukrainian).

23. Stasyuk I.V., Biletskii I.N. Influence of omnidirectional and uniaxial stress on the ferroelectric phase transition in crystals of $\mathrm{KH}_{2} \mathrm{PO}_{4}$ type. // Bull. Ac.Sci.USSR. Phys.Ser., 1983, vol. 4, No 4, p. 79-82.

24. Stasyuk I.V., Biletskii I.N., Styahar O.N Pressure induced pressure phase transition in $\mathrm{KD}_{2} \mathrm{PO}_{4}$ crystals. // Ukr. Fiz. Zh., 1986, vol. 31, No 4, p. 567-571 (in Russian).

25. Blinc R, Žekš B. On the pressure dependence fo the ferroelectric properties of $\mathrm{KH}_{2} \mathrm{PO}_{4}$ and $\mathrm{KD}_{2} \mathrm{PO}_{4}$. // Helv. Phys. Acta, 1968, vol. 41, p. 701-706.

26. Nelmes R.J. Structural studies of KDP and the KDP-type transition by neutron and X-ray diffraction: 1970-1985. // Ferroelectrics, 1987, vol. 71, p. 87-123.

27. Tibbals J.E., Nelmes R.J., McIntyre G.J. The crystal structure of tetragonal $\mathrm{KH}_{2} \mathrm{PO}_{4}$ and $\mathrm{KD}_{2} \mathrm{PO}_{4}$ as a function of temperature and pressure. // J.Phys.C: Solid State. Phys., 1982, vol. 15, p. 37-58.

28. Levitskii R.R., Mits Ye.V., Zachek I.R. Dynamics and some thermodynamic properties of ferroelectrics such as $\mathrm{ND}_{4} \mathrm{D}_{2} \mathrm{PO}_{4}$. / Preprint ITF-81-137R, Kiev, 1982, 40 p. (in Russian). 
29. Levitskii R.R., Mits Ye.V., Zachek I.R., A.A. Volkov, V.G. Kozlov, S.P. Lebedev. Longitudinal and transverse relaxation in $\mathrm{ND}_{4} \mathrm{D}_{2} \mathrm{PO}_{4}$. / Preprint ITF-82-2R, Kiev, 1982, 30 p. (in Russian).

30. Mason W.P. The elastic, piezoelectric, and dielectric constants of potassium dihydrogen phosphate and ammonium dihydrogen phosphate. // Phys. Rev., 1946, vol. 69, No 5, p. 173-194.

31. Mason W.P., Matthias B.T. The piezoelectric, dielectric and elastic properties of $\mathrm{ND}_{4} \mathrm{D}_{2} \mathrm{PO}_{4}$ (deuterated ADP). // Phys. Rev., 1952, vol. 88, No 3, p. 477-479.

32. A.P.Moina. Influence of external pressure on phase transition temperature and physical properties of ferroactive crystals of $\mathrm{KH}_{2} \mathrm{PO}_{4}$ family. Thesis. Lviv, 1997 (in Ukrainian).

33. Haussühl S. Elastischen und thermoelastichen Eigenschaften von $\mathrm{KH}_{2} \mathrm{PO}_{4}, \mathrm{KH}_{2} \mathrm{AsO}_{4}$, $\mathrm{NH}_{4} \mathrm{H}_{2} \mathrm{PO}_{4}, \mathrm{NH}_{4} \mathrm{H}_{2} \mathrm{AsO}_{4}$ und $\mathrm{RbH}_{2} \mathrm{PO}_{4}$. // Z. Kristallogr., 1964, vol. 120, No 6, p. 401-414.

34. Stasyuk I.V., Levitskii R.R., Moina A.P. To be published.

35. Hikita T., Ono Y., Bungo A. Effect if hydrostatic pressure on the ferroelectric phase transition in $\mathrm{KH}_{2} \mathrm{AsO}_{4}$. // J. Phys. Soc. Jap., 1992, vol. 61, No 10, p. 3794-3798.

\title{
Вплив гідростатичного тиску на антисегнетоелектрики типу DADP
}

\author{
Р.Р.Левицький, А.П.Моїна \\ Інститут фізики конденсованих систем НАН України, \\ 290011 м. Львів, вул. Свєнціцького, 1
}

Отримано 23 червня 1998 р.

В роботі досліджується вплив гідростатичного тиску на дейтеровані антисегнетоелектричні кристали типу $\mathrm{ND}_{4} \mathrm{D}_{2} \mathrm{PO}_{4}$. В наближенні чотиричастинкового кластера розраховано вільну енергію системи, отримано рівняння для температури фазового переходу, а також явні вирази для статичних діелектричних проникливостей кристалів. Запропоновано модельні баричні залежності ефективних дипольних моментів елементарних комірок. 3'ясовано деякі особливості утворення дипольного моменту в кристалах з водневими зв'язками цього типу. Зокрема, показано важливість процесів взаємної поляризації диполів.

Знайдено набір параметрів теорії, який забезпечує задовільний кількісний опис експериментальних даних для залежностей від тиску температури переходу й діелектричних характеристик кристалів, що розглядаються.

Ключові слова: $D A D P$, антисегнетоелектрики, тиск, діелектрична проникливість, фазовий перехід

PACS: $77.84 . F$ 